\title{
Revitalisation strategies for modern glass facades of the $20^{\text {th }}$ century
}

\author{
U. Pottgiesser \\ Detmold School of Architecture and Interior Design, \\ Ostwestfalen-Lippe, University of Applied Sciences, Germany
}

\begin{abstract}
Modern glass facades of the early and mid $20^{\text {th }}$ century have always been synonymous with innovative and sophisticated building concepts. These building skins were often established as a feature reflecting international stylistic standards, enhancing the prestige of builders and occupants - although often independent from or even in contradiction with climatic requirements and local conditions. In particular, in Central Europe varying strategies for the revitalisation of modern glass walls, facades and windows have been developed and realised.

Multi-storey and high-rise buildings from the 1950s and 1960s, such as Haus Hardenberg by Paul Schwebes (1955-56) and Europa-Centre by Helmut Hentrich and Huber Petschnigg (1965), both in Berlin, are typical facade constructions. The very diverse approaches of revitalisation of Haus Hardenberg and the Europa-Centre will serve as examples to be compared and described with regard to different planning and decision frameworks. Both buildings have passed through certain episodes of modification and revitalisation. Both are preserving their original appearance, but while the original facade construction of Haus Hardenberg has been maintained and modified, the single glass facade of the Europa-Centre has been totally changed into a double facade system. The architectural design, construction, functions and environmental qualities will be described and evaluated with regard to the original concepts and requirements.

These buildings will be presented addressing their impact on the refurbishment of modern building skins in general and in relation to increasing energetic requirements. In this context newly developed steel profiles have been investigated to be used as an alternative for the revitalisation of protected facade constructions. The way in which Modern Movement buildings in other countries and continents can be adapted to climatic and socio-economic conditions will also be discussed.
\end{abstract}

Keywords: modern heritage, glass facades, windows, steel profiles, energy efficiency, environmental qualities, original architectural concept. 


\section{Introduction}

Modern glass facades of the early and mid $20^{\text {th }}$ century have always been synonymous with innovative and sophisticated building concepts. Based on the first applications in Central Europe between 1910 and 1930, these construction principles have also been used for innumerable commercial and office buildings in other continents later - especially after World War II. Modern glass constructions or building skins were often established as a building feature that reflected international stylistic standards, enhancing the prestige of builders and users - although often independent from or even in contradiction with climatic requirements and local conditions. Combining social and technological concepts of the period, these constructions and their buildings have been an essential stage and a turning point in architectural history. Most of the architects dedicated themselves to construct as lightly as possible, with a minimum of material use and with advanced building technologies to guarantee light-flooded, functional and sane interiors $[1,2]$.

Many early facade constructions have been clearly based on industrial framing and single glazing systems, mostly in connection with small sized glass formats such as Bauhaus in Dessau (1926) or Zonnestraal Sanatorium in Hilversum (1928). Still other facade constructions of that time already opened up the possibilities of nowadays standards in terms of format, flexibility and energy efficiency. Centrosojus in Moscow (1929) has been built as a large curtain-wall double-facade whose original concept has not been realised but envisioned as a ventilated cavity, known as "mur neutralisant" - Le Corbusier's technical approach of dealing with climatic risks of large glass facade surfaces. Haus Tugendhat in Brno (1931) is characterised by huge windows that can be discharged into the lower floor to change the living room into an open air space [3].

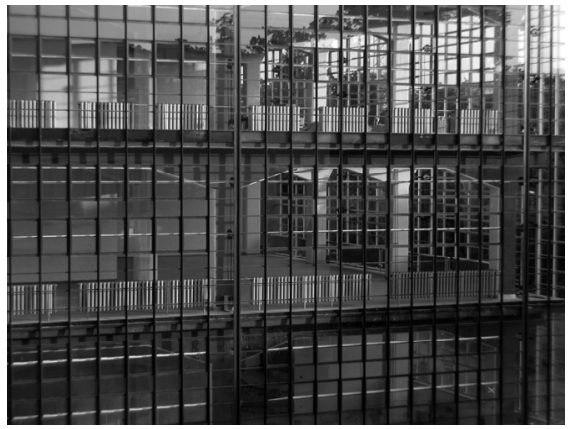

Figure 1: Bauhaus, Dessau, 1926 by Walter Gropius. The facade construction is characterised by the original small sized single glass panes.

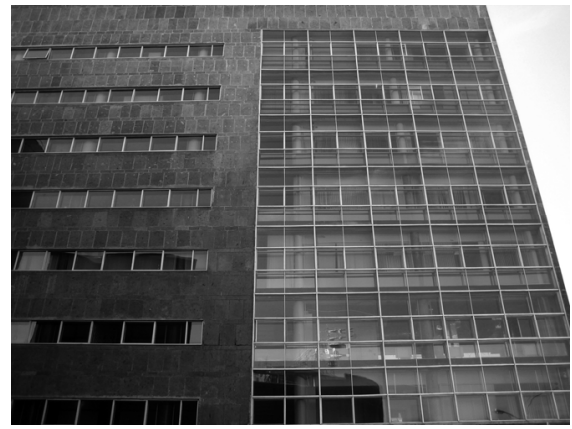

Figure 2: Centrosojus, Moscow, 1929 by Le Corbusier. The double facade has never been ventilated as originally designed; the actual state has been built in the 1970s. 


\section{Case studies}

The focus for the discussion of revitalisation strategies is on multi-storey and high-rise buildings constructed during the 1950s and 1960s which serve for commercial and office use. Haus Hardenberg by Paul Schwebes (1955-56) and the Europa-Centre by Helmut Hentrich and Huber Petschnigg (1965), both in Berlin, represent these building types. The very diverse approaches of revitalisation used for Haus Hardenberg and for the office-tower of the EuropaCentre will serve as examples to be compared and described with regard to different planning and decision frameworks. Both buildings have passed through certain episodes of modification and revitalisation. Both preserve their original appearance, but while the original facade construction of Haus Hardenberg has been maintained and modified carefully, the single glass wall of the EuropaCentre has been totally changed into a new double facade system. The modifications and changes will be evaluated with regard to the original concepts and requirements.

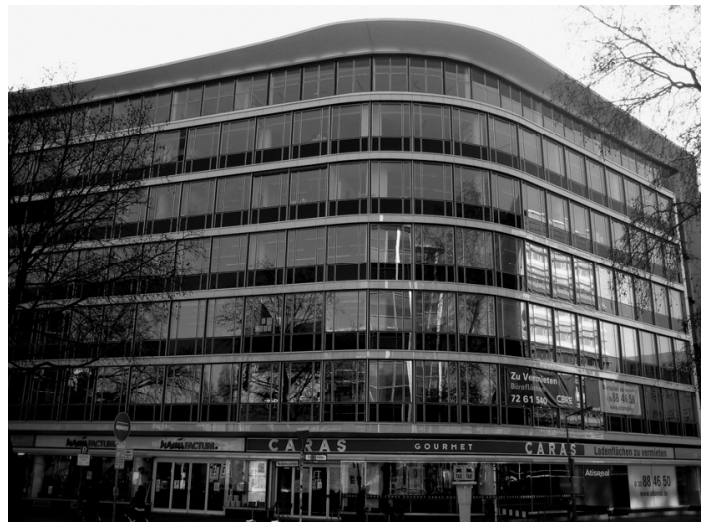

Figure 3: Haus Hardenberg, Berlin 1956 by Paul Schwebes after the revitalisation in 2004.

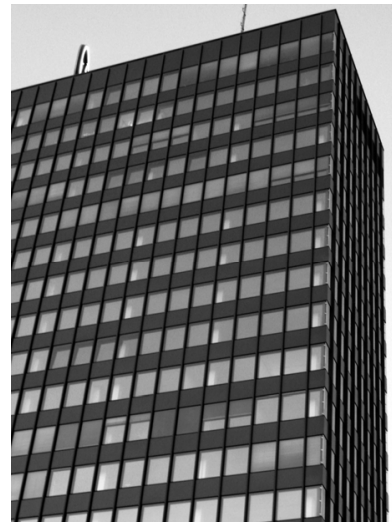

Figure 4: Office-Tower, Europa-Centre, Berlin 1965 by Helmut Hentrich und Hubert Petschnigg after the revitalisation in 2002 .

\subsection{Haus Hardenberg: original construction and revitalisation}

Based on a trapezoid ground plan, the building is affected by the dynamic curved edge and the enormous, thin and widely overlapping canopy. The front facade is horizontally structured by large ribbon windows. The building is reminiscent of 1920s corporate architecture, and it is considered to be one of the most beautiful buildings of the 1950s in Germany [4]. 
The street facade is divided into three zones and displays a classic structure with a ground floor that is set-off and sheltered by an awning while the main floors and the stepped attic are set-off with a canopy. The five upper floors are characterised by the ribbon windows, which are only interrupted by the prominent concrete floor slabs. These are clad with white, non-transparent glass panes known as "Detopakglas", which is also used in black for the parapet panels. The ribbon windows are made up of storey-high window elements with large vision panels in the middle, and slender casements at each side - similar to the "Chicago Window". The window units are framed with small vertical steel profiles and the casements consist of very thin steel frames, which are painted black on the exterior and white on the interior. The double casements build a small cavity with thermal insulation. The slender dimension of the profiles, together with the selected materials, lends an elegant appearance to the building. The shop windows in the basement are made out of brass-coloured anodised aluminium frames.

The fundamental idea during the revitalisation campaign in 2004 was to maintain the integrity of the protected commercial building, particularly the elements that render the spirit of the architecture of the 1950s.

One focus was the restoration of the front facade, whose appearance is formative for the building and the townscape around Ernst-Reuter-Platz. The restoration was aiming to keep as much of the original framing and materials as possible, as well as paying close detail to the elaborate treatment of the historic structure. The profiles of the existing facades were cleaned, broken glass panes and sunscreens were replaced and window hard ware and hinges were upgraded. The adaptation of the steel-framed window elements to today's requirements of thermal and noise protection is an example of substantial workmanship. The original single glass pane of the inner casement has been exchanged by a coated k-glass pane. An additional front lighting concept has been developed and added to support the properties of the building, incorporating the canopy and an advertising ribbon over the ground floor shop windows. Only the desolate condition of the staircase facades at the rear of the building required the installation of new aluminium glass facades with thermal breakers. The building services have been partly modernised to respond to comfort and security requirements. In addition to the existing heating system, the shops and offices are ventilated and air conditioned.

\subsection{Europa-Centre: original construction and revitalisation of the tower}

The Europa-Centre was designed as an office and shop-in-shop-system according to American prototypes - dominated by the office-tower. The building is located at Breitscheidplatz, which was heavily destroyed during World War II. The area became known as the "New West" of Berlin and is dominated by the ruin of Kaiser-Wilhelm-Gedächtniskirche and the new Gedächniskirche dating from 1960. Its architect Egon Eiermann acted as artistic adviser for the EuropaCentre. Both buildings became emblems of West-Berlin in the 1960s.

The facades of the lower buildings and the office-tower are displaying different types of glass walls with aluminium framework. The office-tower is 
characterised by a curtain wall construction with a modular grid of $1,875 \mathrm{~m}$ and by large, non-operable vision panels and opaque breast wall fillings, which are alternating vertically between the projecting posts. The concrete skeleton construction with two rows of columns has a grid of $8,00 \mathrm{~m}$ supporting flat concrete slabs that are covering a ground area of $47,30 \times 17,30$. The columns are set off the floor perimeter at about $1,00 \mathrm{~m}$ so that the curtain wall facade is enveloping the entire building volume as it is typical in International Style office buildings from the 1960s.

The interior is characterised by a very compact and centrally located supplyunit, which comprises two staircases that are nested into each other, as well as elevators, kitchenettes and restrooms. Two office units with artificially lit corridors project from the supply-unit at each side.

The revitalisation of the office-tower into a modern office building took place in 2002. One of the focuses was the restoration of the curtain wall construction, whose appearance is formative for the townscape in the "New West". The other objective was to transform the interior into an efficient work space, in terms of comfort and equipment.

The original curtain wall construction was demolished and replaced by a double facade out of aluminium with box-type-windows. The preservation of the outer appearance with its slender vertical profiles was considered and attained by designing an exterior, single glazed layer in front of an inner layer of insulating glazing that has thicker profiles. While the inner layer offers thermal protection, the outer layer protects against atmospheric conditions, such as the sun, wind and rain. The new facade obtains operable windows at the inner layer and slots at the outer layer, allowing the opportunity to have natural ventilation. Through these means, the rooms formerly used for the air-conditioning plants were now converted into office spaces.

This facilitates that different office layouts, such as cell-, group-, combination-, or open-space-offices, are available for use. All installations, such as heating and ventilation pipes, electricity and data cables are installed in a circular media channel alongside the facade. This installation principle also allows for more transparent partition walls.

\section{Revitalisation of modern glass facades}

\subsection{Typical weaknesses and damages}

The biggest weakness of 1950s glass facades such as Haus Hardenberg is the high proportion of the glass area that is in generally over $50 \%$ of the overall height, so that high thermal loads are brought into the building. In combination with the typical slender floor structure of the 1950s buildings, the facades continue to allow good natural lighting and ventilation on the other hand.

Typically, their hydro-thermal performance is restricted by an insufficient thermal insulation of the steel-framed windows, including leakage at profiles, rather than visible signs of damage due to corrosion of the window profiles or 
problems with the interface with other building elements. Steel profiles that are not separated work as thermal bridges, and most of them have significantly deteriorated and warped, allowing moisture infiltration.

Compared to the thermal insulation of the steel-frames the glazing units often already differ from 1930s single glazing. In Haus Hardenberg doubled steel frames have been used to increase the thermal-insulation. Each frame contains a single glazing and together they form an insulating air cavity of a few centimetres. Another option has been a spitted single glazing that has been used in the Unité d'habitation in Berlin 1958. This kind of early insulating glazing was made out of a single glass pane. Even if their U-Values differ strongly from those of actual glazing units both facade construction have been much better than in the 1930s.

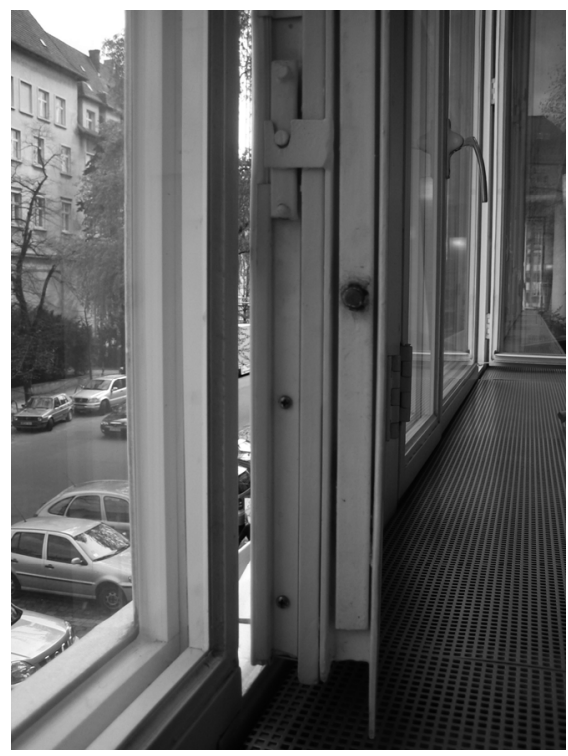

Figure 5: Double steel frame, Haus Hardenberg.

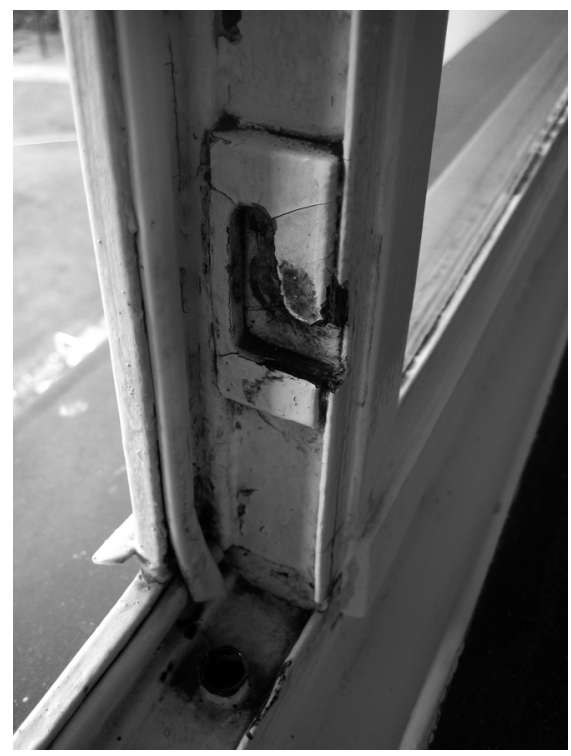

Figure 6: Single steel frame, Unité d'habitation.

Compared to the 1950s the glass facades of the 1960s already show the transition from manufactured to industrial produced constructions that were now mostly in aluminium and the beginning of completely air-conditioned interiors.

These early aluminium constructions suffer from an insufficient thermal insulation too, as many profiles are not separated. Many of them show problems in the area of joining sot that leakage and moisture infiltration are common. Very often sun protection has not been installed or has been applied not efficiently. 


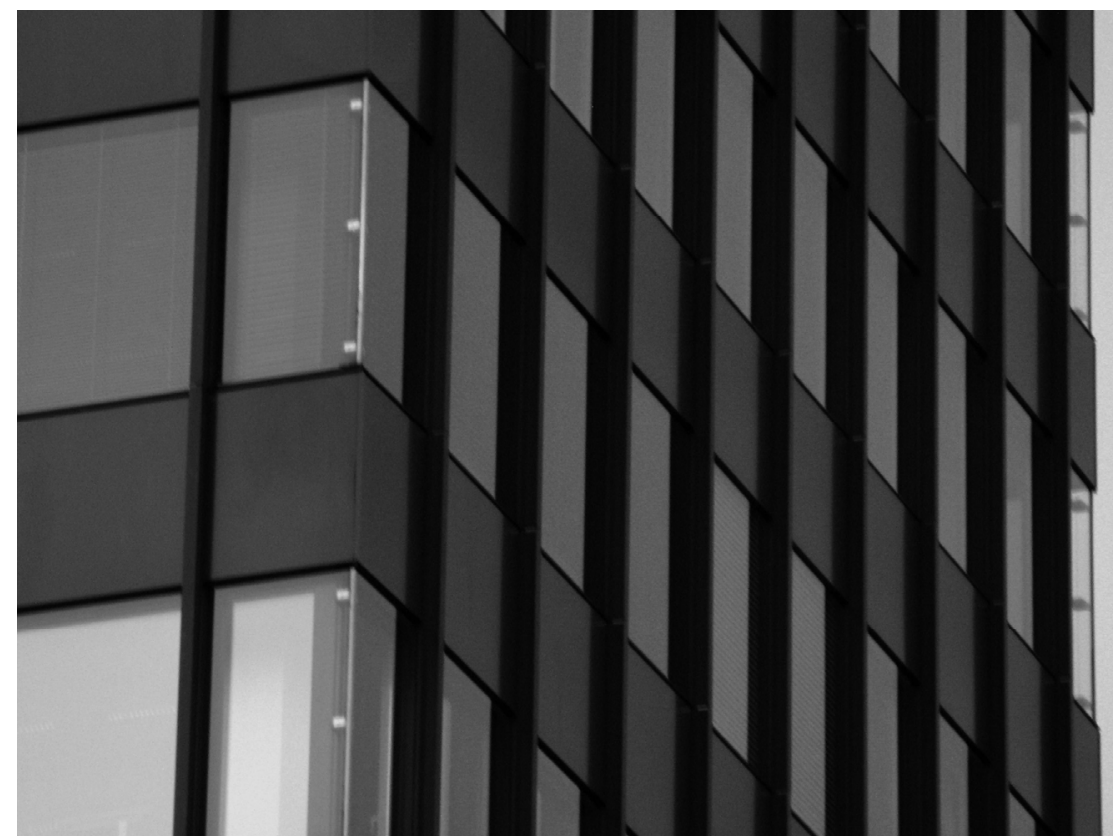

Figure 7: The new double facade system of the Europa-Centre from 2002 is identical to the original curtain wall from 1965. It has been replaced to enable natural ventilation in the offices in major parts of the year. The box-type-window has been built out of profiles similar to the originals to create a narrow cavity of $12 \mathrm{~cm}$. Behind the outer single glazing the cavity includes a lamellar store for sun protection.

\subsection{Strategies for revitalisation}

In Central Europe, two main strategies and technologies for the revitalisation of modern glass facades in protected buildings have been developed and realised. Both are aiming at preserving the original appearance, while offering different solutions with regard to their adaptability to the requirements of environmental comfort, thermal and noise protection and those of an appropriate working atmosphere. The strategies are as follows:

- Restoration of original steel or aluminium construction with careful modifications of single elements, such as exchange of the original glazing against improved, insulating ones; the application of additional glass layers in the form of composite windows or additional window layers; the refitting of sealing gaskets to the window frames. This first approach does not generally permit an efficient thermal protection, since frames and glazing often keep close to the original values and thermal loads. In this way, energy consumption is more difficult to reduce and air conditioning is often needed; 
- Replacement of the original construction with a new facade system including insulation glazing, or the introduction of a double facade system with a singleglass layer on the outside and a secondary insulation glazing on the inside. Both solutions enable minimization of the energy consumption and optimisation of interior comfort through better ventilation as well as sun shading and heat protection. A critical point is to rebuild an authentic appearance of the structure and the inner and outer surfaces.

Such good example for authentic revitalisation is Tour Nobel (now Tour Initiale) by Jean de Mailly and Jacques Depussé (1966) in Paris, La Défense. The glass facade of Tour Nobel has been designed by the engineer Jean Prouvé who used curved glass units on the corners of the tower, which was at that time quite unusual. The facade has been renovated in 2003 identically to the original appearance so that the plane surface has been kept.

While the examples of Europa-Centre and Tour Initiale are showing careful and authentic revitalisations of the facade, the replacement of entire facade constructions is nevertheless bearing the risk of losing authenticity. This can be seen at the revitalisation of Tour Zamansky by Édouard Albert (1971) at the Campus de Jussieu in Paris. The facade of the tower has been exchanged in 2009 and is unfortunately not authentic to the original vertically structured grid of profiles that was providing a specific visual depth to the entire construction [5].

Recently the revitalisation of the UNESCO building (1958) by Marcel Breuer, Bernard Louis Zehrfuss and Pier Luigi Nervi in Paris has shown a disputable approach. Mayor facade elements have been substituted and only the brise-soleils have been kept to remember the original appearance. In fact the climatic concept is now completely based on air conditioning instead of realising a durable conception of energy efficiency with natural and cross ventilation [6].

A possibility of authentic reconstruction could be the exchange of historical steel profiles by slender thermally separated steel profiles with good thermal insulation. Those are used for air-conditioning plants and for the stabilisation of plastic window frames. The actual research at Ostwestfalen-Lippe is comparing the proportions of both kind of steel profiles and the implementation of the thermally separated profiles into historical and existing facade systems.
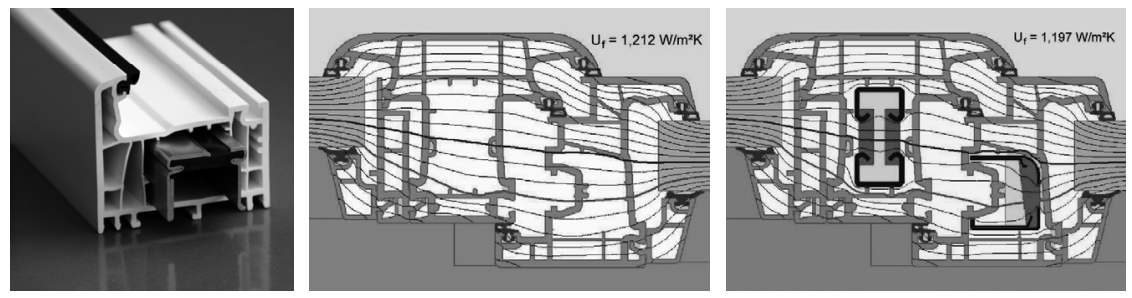

Figure 8: Thermally separated steel profiles. 


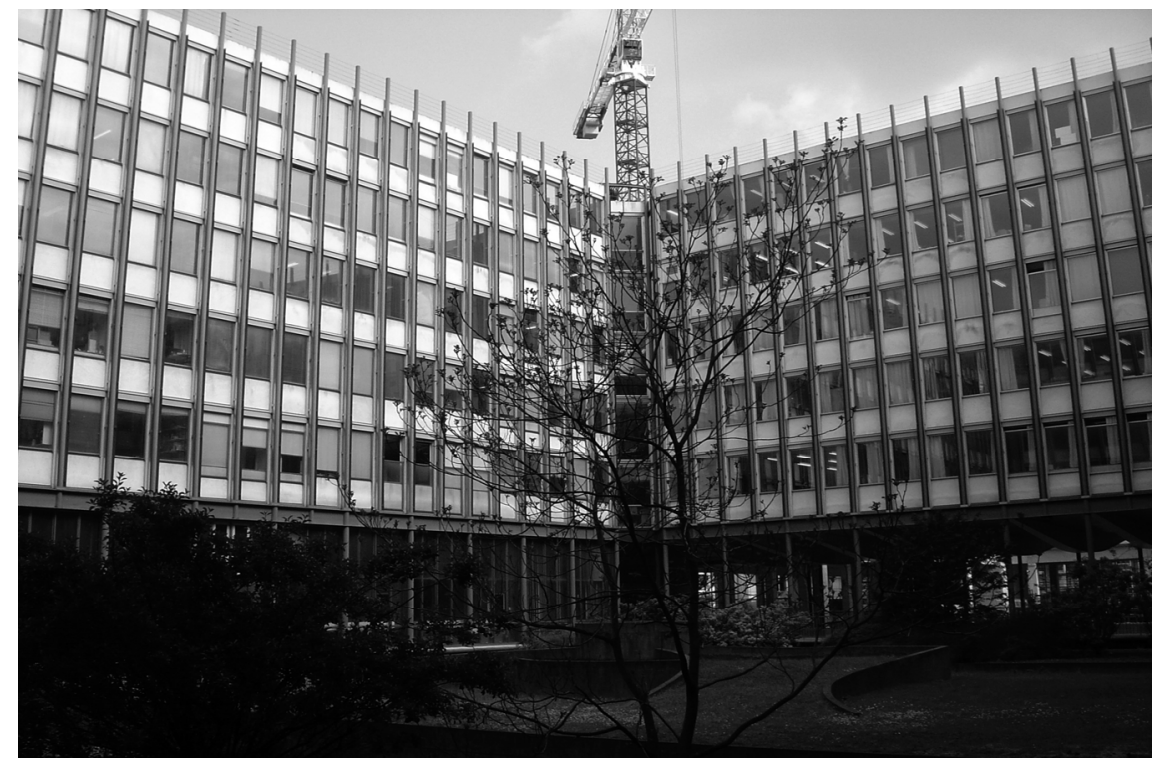

Figure 9: The new university Campus de Jussieu (CUJ) in Paris was designed by Édouard Albert from 1964 to 1971.

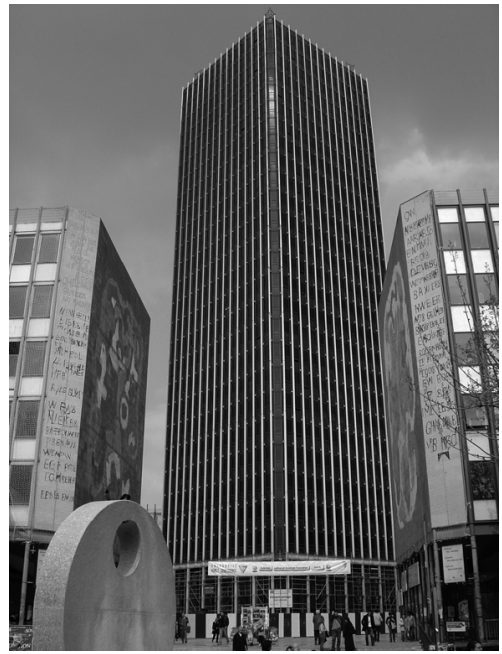

Figure 10: Tour Zamansky, Campus de Jussieu, Paris, 1971 by Édouard Albert.

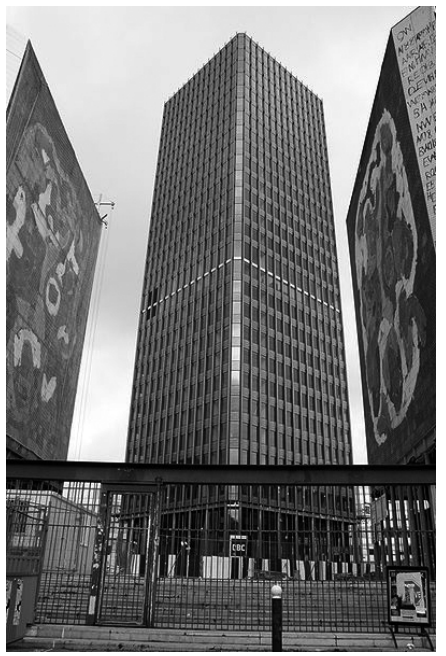

Figure 11: Tour Zamansky in 2009 with a new facade system that unfortunately does not resemble the original vertical grid of the original facade. 


\subsection{Impacts on the revitalisation of modern buildings worldwide}

Similar to these European examples, occupants all over the world more and more call for durable and sustainable facade constructions which can provide increased thermal and noise protection. These optimised constructions are seen as criteria for quality of life and technological progress and also as a climatic necessity. This requires upgrading of energetic parameters in connection with comfort requirements [7].

The BEMGE by Oscar Niemeyer (1953) in Belo Horizonte is a further example from the period under discussion in Brazil that should be seen in relation to its impact for future revitalisations worldwide. BEMGE is fully glazed between the concrete floor slabs while the steel framing is reminiscent of early industrial glazing, similar to those applied in early modern European buildings. To what extent can the experiences and methods from Central Europe be transferred and adopted to other climates and continents, such as Brazil, a region with many post-war modern buildings?

Since Brazil has relatively few periods of low temperatures, overheating is a main cause of concern and also the penetration of noise and polluted air from increasing inner city traffic. In consequence working conditions are far from being acceptable so that additional sun and glare blinds and air condition units have been installed individually by the occupants. On the other hand natural cross ventilation still is seen as a tradition and necessity of indoor comfort by the users. In the case of BEMGE it could be possible to add an additional inner facade layer so that the existing glass wall construction could be preserved while sun shading and intense natural ventilation could be optimised in the new cavity. This would finally enable a comfortable work atmosphere in the offices.

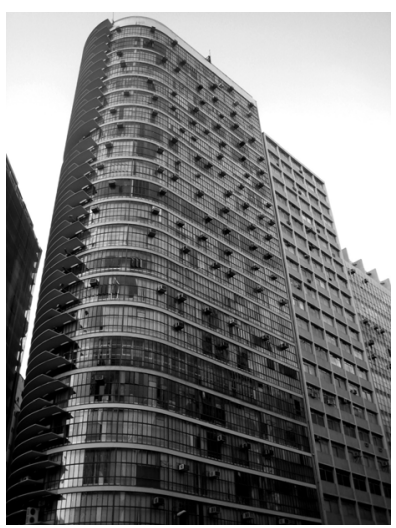

Figure 12: BEMGE, Belo Horizonte, 1953 by Oscar Niemeyer in 2006.

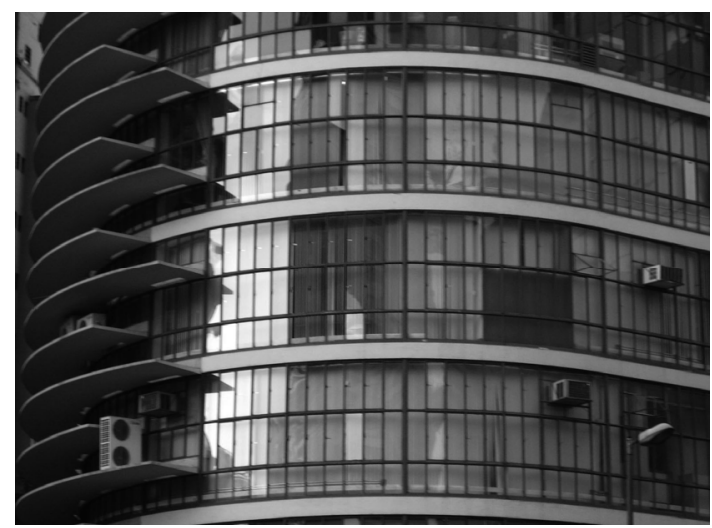

Figure 13: The BEMGE shows a functional treatment of northern facade with specific brise-soleils that contain small vents to support ventilation, but still these means could not prevent overheating of the interior. 


\section{Concluding remarks}

Especially now at a moment of cogitation about the general framework of an economically driven world the shared recognition of the cultural and social value of modern heritage can become more important and more relevant for the society's identification. Anyway the continuing economic viability of both the icon and the ordinary modern heritage will always be a strong argument to find supporters and investors. In order to be successfully in this discussion, the specific character of the architecture and urbanism of the Modern Movement must be emphasised.

This has also been expressed in one of the latest and most comprehensive publications about the preservation of modern architecture:

"Additional issues that will shape the evolution of the dialogue concerning modern heritage include: the continued expansion of the understanding of modernism through further study and preservation efforts in Asia, Africa, and Latin America; the inclusion of landscape design, urban planning, and interior design as integral to the language and forms of modern architecture and, therefore, its preservation;...

"Efforts to incorporate recognition of the importance of interior spaces in the early stages of the interpretation of modern architecture will not only help maintain its integrity, but also allow for more flexibility in the future reassessment of the building." [8].

The presented European approaches for the revitalisation of modern glass facades can be adapted to other climates and can serve as a general strategy for other modern heritage worldwide. It will be important to adjust the strategy as well to the specific economic conditions. This will over all allow to start a discussion about the cultural and social value and of course to reduce overheating, to increase thermal and noise protection and finally to save energy.

Until recently, and compared to the implementation of other relevant and specific planning requirements and regulations, the particularities of climatic conditions such as temperature profile, wind directions, sunshine duration or humidity have often been neglected. Good planning has to work with and not against the local climate. One must be able to "read" the specific macro- and micro-climate of a building, in order to define and to develop, in an early stage of the planning, suitable strategies for energy economy and a long-term use of protected buildings. In the same manner the occupants and their cultural differences have to be made part of the process.

\section{References}

[1] Banham, R., The Architecture of well-tempered environment, University Of Chicago Press: Chicago, 2nd edition 1969.

[2] Kelley, S. J., An Image of Modernity. An American History of the Curtain Wall. Curtain Wall Refurbishment. A Challenge to Manage, Proceedings 
International DOCOMOMO Seminar, January 25, 1996, DOCOMOMO International: Eindhoven University of Technology, pp. 16-21, 1997.

[3] Pottgiesser, U., Schnittstelle Fassade - International und Integral. Innovative Fassadentechnik 01/08, Ernst \& Sohn: Berlin, pp. 3-7, 2008.

[4] Dorsemagen, D., Büro- und Geschäftshausfassaden der 50er Jahre. Konservatorische Probleme am Beispiel West-Berlin, TU Berlin Architektur: Dissertation, 2004.

[5] Lemoine, B., Frankreich 20. Jahrhundert. France 20th century. Birkhäuser: Basel, Berlin, Boston, pp. 74, 126, 134, 2000.

[6] Fernandez, V., La Façade Vitrée de l'UNESCO. Entre Soleil recherché et soleil redouté, Ecole d'Architecture de Paris-Belleville: Memoire 3ème Cycle, 2002.

[7] Pottgiesser, U., Modern Glass Walls on the Way to Sustainability. Comparing Examples from Germany and Brazil. Proceedings 10th International DOCOMOMO Conference, IOS Press BV: Amsterdam, pp. 331-336, 2008.

[8] Prudon, T. H. M., Preservation of Modern Architecture. Wiley: Hoboken, pp. 20-22, 2008. 